\title{
Restoration of Historic Windows: Methodology and Case Studies
}

\author{
Edward A. Gerns ${ }^{1}$ and Sarah K. Van Domelen ${ }^{2}$ \\ ${ }^{1}$ Wiss, Janney, Elstner Associates, Inc., 10 South LaSalle, Suite 2600, Chicago, Illinois, USA, \\ egerns@wje.com \\ ${ }^{2}$ Wiss, Janney, Elstner Associates, Inc., 10 South LaSalle, Suite 2600, Chicago, Illinois, USA, \\ svandomelen@wje.com
}

\begin{abstract}
All too often, the original windows are unnecessarily removed and replaced from historic buildings. In some instances, replacement is justified due to the extent of deterioration resulting from years of deferred or inappropriate maintenance. However, often historic windows are unnecessarily replaced as a result of incorrect assumptions or misinterpretation of their condition. Alternatively, a designer may believe that a new window will perform better, require less maintenance, increase energy efficiency, or just last longer than the existing original windows. This may not be the case. This paper will address issues related to the evaluation and restoration of historic wood and metal windows. An overview of the methodology used by the authors to evaluate the condition of windows and determine repairs that are necessary to maintain structural integrity, repairs that are necessary to address air and water infiltration, and repairs relative to aesthetics and function, will be presented.
\end{abstract}

Keywords: Wood Windows, Steel Windows, Evaluation, Restoration.

\section{Introduction}

Windows are a character defining architectural feature of almost all buildings. At a functional level, windows provide natural light and fresh air, and sometimes a means of egress, to interior spaces. Over the years, many building owners have opted to replace rather than restore original historic windows. Replacement window manufacturers tout these products as a means of providing increased thermal performance and 'no maintenance.' However, in reality, replacement windows may have unrealistic payback periods, and many new windows are actually 'not maintainable.' Alternate materials such as aluminum, and more recently vinyl and fiberglass, have been used to replace historic original windows. In many instances, when considering life cycle costs as well as maintaining historic fabric, repairing and restoring historic windows is not only environmentally and preservation sensitive, but also economical. Thermal upgrades are also possible by installing storm windows at a macro scale, or replacing or installing weather-stripping at a micro level.

\section{Evaluation Methodology}

Determining the general condition of any historic window is critical to developing a restoration program. The condition of windows can vary significantly based on orientation and location within the facade. Often, coatings and/or previous interventions may be misleading relative to the actual condition of the window components. Determining the extent and location of hazardous materials is also critical to accurately developing an appropriate scope of work. Based on the findings, special provisions for remediation may be required. In some instances, 
hazardous materials may have been installed during original fabrication or installation and may be concealed by the various components of the windows.

The general methodology used by the authors when evaluating historic windows includes document review, comprehensive or representative close-up interior and exterior surveys, investigative openings, and partial or complete window disassembly. Based on the available funds and access, all of these tasks may not be possible or practical. Much like any aspect of building restoration, building owners should understand that gathering more information during the initial evaluation can reduce the potential for unanticipated added costs once work begins.

\subsection{Document Review}

When existing building drawings or specifications exist, review of these documents can provide insight into the construction of the windows, as well as the method of anchorage to surrounding construction. Particularly in the case of wood windows, the windows were often constructed onsite to accommodate variation in the as-built openings, and original drawings may be limited or nonexistent. In the case of metal windows, the original manufacturer can sometimes be determined by comparing window profiles with resources such as Sweet's Catalogue. Review of documents detailing past maintenance or repairs can also help identify existing conditions.

\subsection{Visual Survey: Exterior}

Close-up observation of the exterior portions of the windows is critical to determine the extent

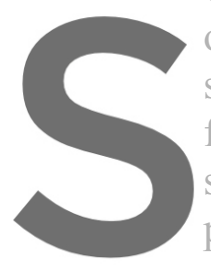
of intervention that may selected review must of facades and different sample of each should be included. Observatic perimeter seals, and glazing putty and stops,
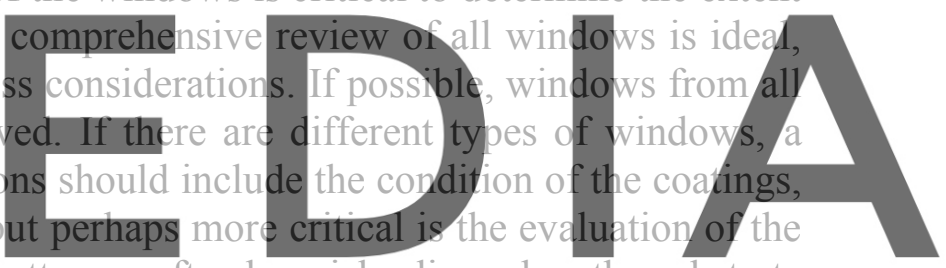

substrate material. Peeling paint and missing putty can often be misleading when the substrate and side ralls opthe sash, and the siland bottom rail op the sash exhibit the most deterioration

Probing these areas with an awl can be an effective means to assess the condition of the substrate for both wood and metal windows. In the case of wood windows, the awl will readily penetrate rotted areas. Areas of corrosion or section loss in metal windows may be visually apparent, previously installed fillers can often be detected by tapping areas with the awl.

If the water resistance of the windows is in question, performing water testing using various techniques can provide an indication of the source(s) of the leakage. It is important to understand, however, that historic windows cannot meet standardized testing criteria for new windows, and that failure to meet current standards for water resistance is not a basis or justification, in and of itself, to replace the windows.

\subsection{Visual Survey: Interior}

A close-up examination from the interior is also critical to evaluate the existing window conditions. Depending on the building occupancy, it may be easier to perform a comprehensive survey from the interior, but if that is not possible, rationale similar to that described above should be applied when selecting specific locations for review.

Review of the windows from the interior can provide an indication of the water resistance of 
the existing assemblies. Damage such as peeling paint, blistering plaster, and discoloration of finishes may be an indication of water infiltration. Review of the specific location of the damage can provide an indication of the source of water. While the window itself may be the source of the infiltration, other factors may be contributing including lack of flashings, failed perimeter sealant, condensation, or thermal bridging. Inventorying the existing hardware and operation of the sash should be included if the intent is to restore functionality of the windows. Often the windows have been painted or sealed closed, so evaluation of functionality can be challenging.

\subsection{Investigative Openings and Disassembly}

Investigative openings can be helpful in determining window anchorage details, as well as the configuration of the window-to-wall interface at the perimeter of the assembly. Concealed conditions and deterioration may also be revealed. Removing selected windows, in part or as a whole, can also provide valuable information with respect to the assembly and components. The geometry of weather-stripping and component profiles can be difficult to determine without removing operable portions and the frames.

\section{Restoration Approaches}

Once the investigation has been completed, gaining an understanding of the Owner's expectations is necessary to develop an appropriate restoration approach. While comprehensive restoration is ideal to achieve a consistent end result, it is often not necessary or justified. The

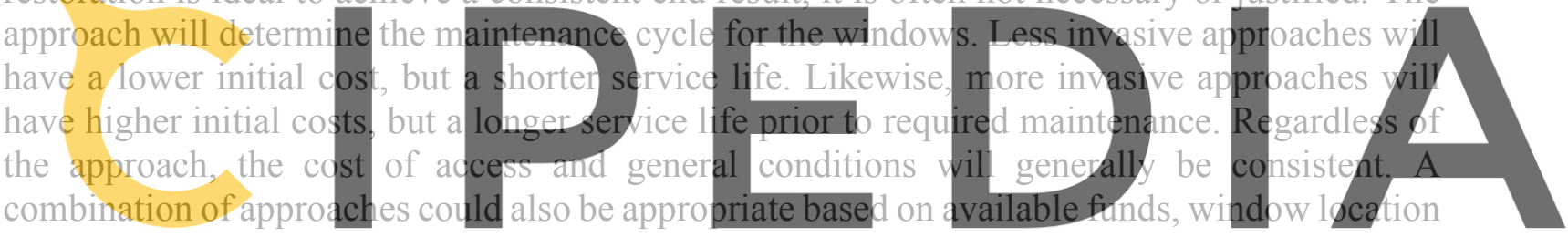

or exposure, or other factors. A brief description of various restoration approaches follows.

Register for free at https/fwww.scipedia.com to download the version without the watermark (fich

If the substrate is generally in good condition, removing areas of loose coating, sanding, and applying a new coating system can protect the historic fabric of the windows. Replacing deteriorated glazing putty is often performed concurrently. This approach is obviously the least invasive and lowest cost when considering the entire window assembly.

\subsection{Stripping and Painting}

Based on the condition of the substrate material, or to determine the condition of the substrate, complete removal of the existing coating may be necessary. In the case of wood windows, paint strippers are most effective. If the existing coatings contain lead, certain strippers can both remove and capture the coatings for disposal. For steel windows, paint strippers can also be used, but abrasive blasting can frequently be more effective and economical. If performed properly, blasting can effectively remove existing coatings at inside corners and crevasses. For wood windows, hand tools are often necessary to remove remnants from these areas. It is important that all chemicals and other residue be completely removed from the surface of the window prior to performing repairs or applying a new coating system. 


\subsection{Localized Repairs, Dutchman Repairs, and Component Replacement}

Depending on the size and extent of substrate deterioration, repairs can vary from patching of localized areas of rotted wood or corrosion, to replacement of complete members. Localized rot in wood windows and corrosion of metal windows can be removed and the area filled with a compatible repair material such as an epoxy filler. In both instances, particularly wood, it is important avoid applying the filler as a means of building up the surface of non-deteriorated areas. This can lead to accelerated deterioration of the wood, since the filler can trap moisture. This is less of an issue with metal windows, but achieving a uniform surface is not necessary unless the area has the potential to hold water (e.g. the upward facing surface of a sill).

More extensive deterioration may require replacing portions of a member (dutchman repair) or a complete member. The most common application of dutchman repairs is for the lower portions of jambs, while complete replacement is often necessary for sills. Ideally, rot resistant old growth woods such as mahogany are desirable for dutchmen in wood windows. Deteriorated portions of the members are cut away and the new piece is anchored to sound substrate. Treatment of the joint between the dutchman and the original material should be considered to limit the potential for water to reach the untreated end grain of both pieces. Fasteners can be countersunk and concealed with a wood plug.

In the case of steel dutchmen, it is likely that the original profile of the steel assembly is no longer manufactured, and the new pieces may need to be fabricated by building up smaller pieces to generally match the profile. A perfect match using this approach is typically not

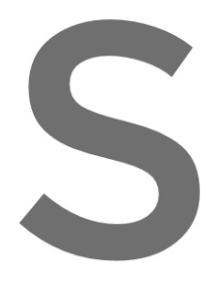
possible due to the difter approach for steel dutching procedure should be part smooth to the adjacen 3.4 Glazing
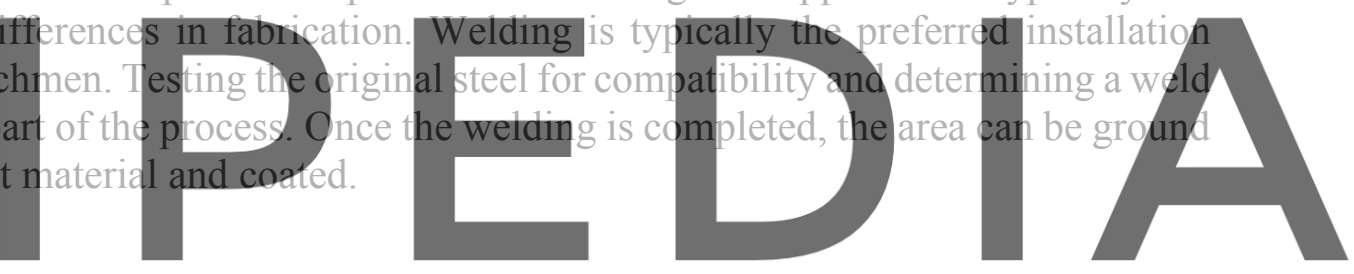

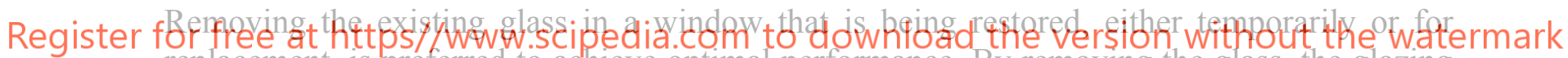
replacement, is preferred to achieve optimal performance. By removing the glass, the glazing pocket can be prepared and coated prior to reglazing. From a preservation perspective, the glass should ideally be retained and reused. However, a relatively high rate of breakage is almost unavoidable in many instances, which can increase the appeal of comprehensive reglazing.

Often, installing replacement insulating glass units (IGUs) is considered as a thermal improvement. This approach can introduce challenges relative to the width of the glazing pocket and the weight of the sash. Conventional IGUs are typically 1 inch thick, while historic glass is typically between $1 / 8$ inch and $1 / 2$ inch thick, depending on the size of the opening. With thicker replacement glass, the glazing pocket must be made wider by either modifying the sash component, reducing the profile of the putty and glazing points, or modifying the glazing stops, all of which have the potential to significantly reduce the wind load resistance of the window. The frame and hardware should also be evaluated to ensure that they can support any added weight. Recently, glass manufacturers have introduced thinner IGUs that can fit into existing glazing pockets, but at a significant cost increase over reusing the existing glass or using conventional IGUs. Other replacement glazing options, such as laminated glass, can also be considered, but many of the same considerations discussed above will still apply. 


\subsection{Hardware}

Based on the condition of the existing hardware, replacement hardware may be necessary. Matching original hardware may be possible, but is often challenging if the components are no longer manufactured. Options can include salvage sources or potentially using hardware from other windows on the building. If limited original hardware is available, sets of original hardware and replacement hardware can be grouped by window.

\subsection{Weather-Stripping}

Historic windows typically used metal weather-stripping at all operable interfaces. For wood windows, the geometry of the weather-stripping is somewhat forgiving, and a similar metal profile is often available that can fit the assembly. At concealed interfaces, modern weatherstripping materials such as foams and plastics may also be used. Historic weather-stripping for metal windows was typically fabricated specifically for a particular profile, and is most likely no longer available. Salvage and reuse of weather-stripping may be possible under certain circumstances, but given the tolerances of fabrication and operation, once removed, it is likely not realistic to reinstall. For this reason, weather-stripping options for metal windows generally include custom fabrication of new weather-stripping to match the original, or creative application of readily available modern components.

\section{Case Study: Wood Windlows}

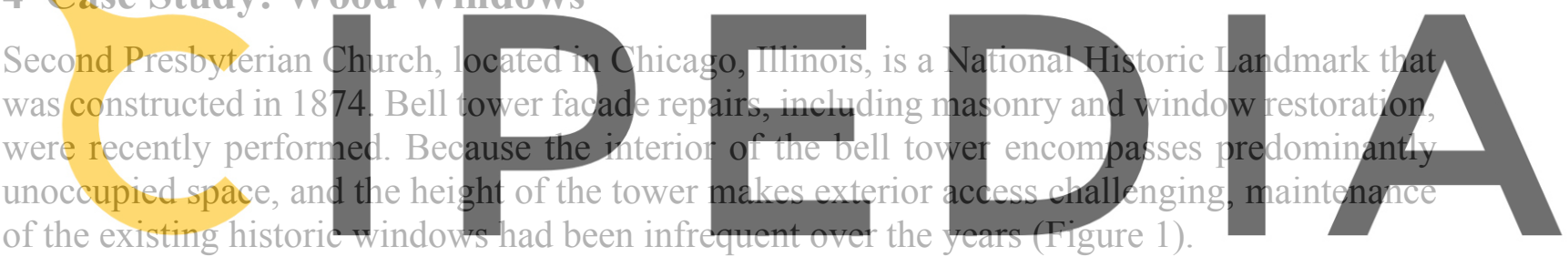
of the existing historic windows had been infrequent over the years (Figure 1).

\section{Register for free at https//www.scipedia.com to download the version without the watermark}

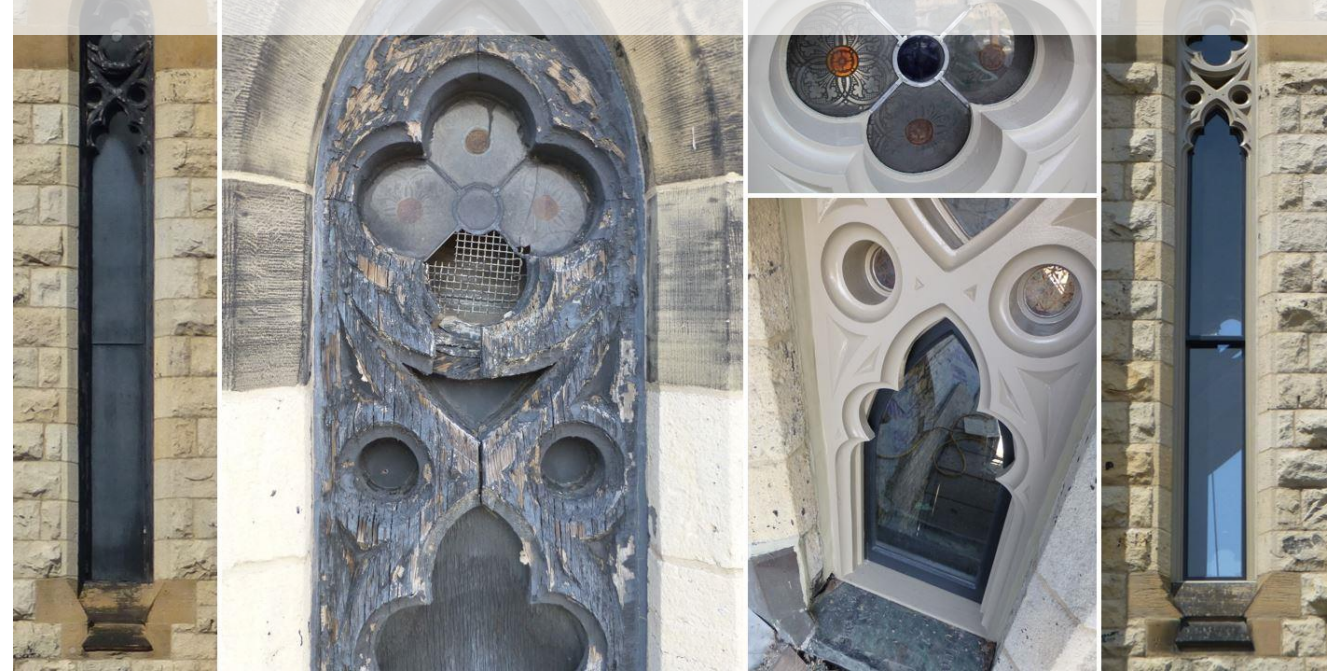

Figure 1. Typical window conditions before (left) and after restoration (right). 
The exterior evaluation of the windows was performed from an aerial lift, which allowed access to all of the tower windows. The surfaces were probed with an awl, but no investigative openings were created. On the interior, access was limited based on the proximity of an interior stair. Conditions included wood decay at various exterior locations including sills, the base of jambs, and at decorative tracery. Several of the sash were missing, and the frames had been boarded up. Portions of the leaded art glass were broken or missing. Since the windows were likely built on site during construction, no original drawings or specifications existed.

Based on the owner's inability to ensure that resources could be dedicated to future maintenance of the windows, a comprehensive restoration approach was selected to maximize service life. Repairs included complete removal of existing coatings using a chemical stripper, replacement of deteriorated sills and tracery, dutchman repairs at the lower portions of jambs, replacement of sash, hardware, and weather-stripping, removal and restoration of the art glass, interior and exterior painting, and perimeter sealant replacement (Figure 2). The replacement sash were fabricated to match the profiles of the limited sash that remained. Although the original sash were likely glazed with leaded glass based on historic photos, the new sash were glazed with clear laminated glass due to budgetary constraints. The decision was also made to seal the perimeter of the glass with silicone sealant, rather than traditional glazing putty, to reduce the overall maintenance cycle. Based on the location of these windows, the substitution is not visually apparent. Finally, the colors of the new exterior coatings were selected based on paint analysis performed on other windows at the church and the historic photos.
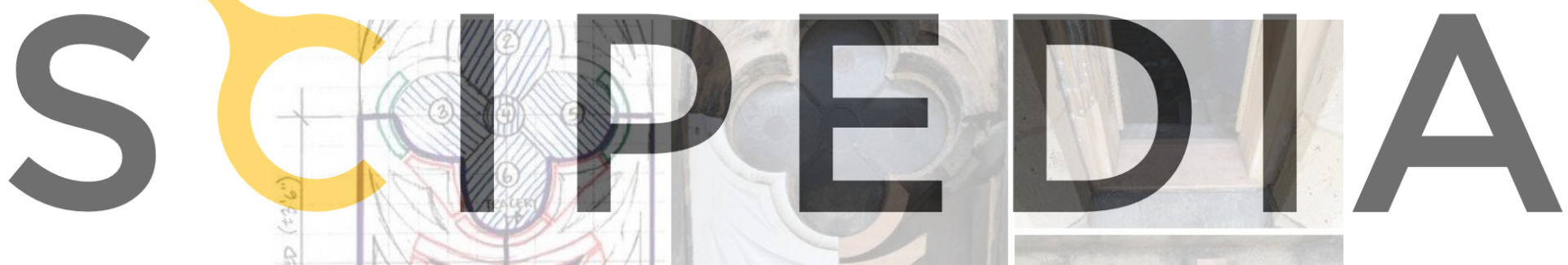

Register for free at https//www.scipedia.com to download the version without the watermark

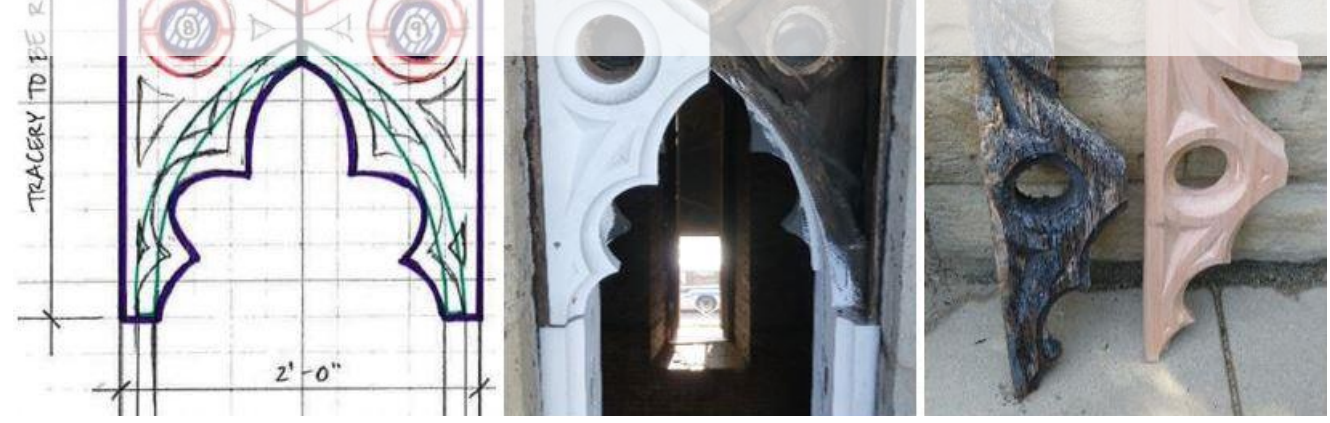

Figure 2. Sill replacement and jamb dutchmen (upper right) and tracery replacement.

Various challenges were encountered throughout the project. At the outset, it was difficult to find an experienced window restoration contractor that could perform the necessary onsite restoration of the existing frames. Once on board, the contractor encountered challenges obtaining the desired wood species for replacement elements and dutchmen. In the end, the challenges were overcome, and the end result was a successful wood window restoration. 


\section{Case Study: Steel Windows}

30th Street Station, located in Philadelphia, Pennsylvania, is the second busiest train station in the United States. The building is iconic in the Philadelphia community and is listed on the National Register of Historic Places. Constructed in 1934, one of the defining architectural features is the fenestration system, which includes rolled steel casement windows set into cast iron curtain walls that are located between limestone clad piers (Figure 3). As part of a comprehensive facade restoration project, an evaluation of the windows was performed. Due to security and access restrictions, the evaluation was limited. The window assessment included a visual survey of select areas on the interior and exterior. In addition, one of the steel windows was removed to document the interface geometry and concealed conditions. Materials testing of the steel and cast iron, and a finish analysis to determine the original color scheme, were performed. A hazardous materials survey and testing were performed by the owner.

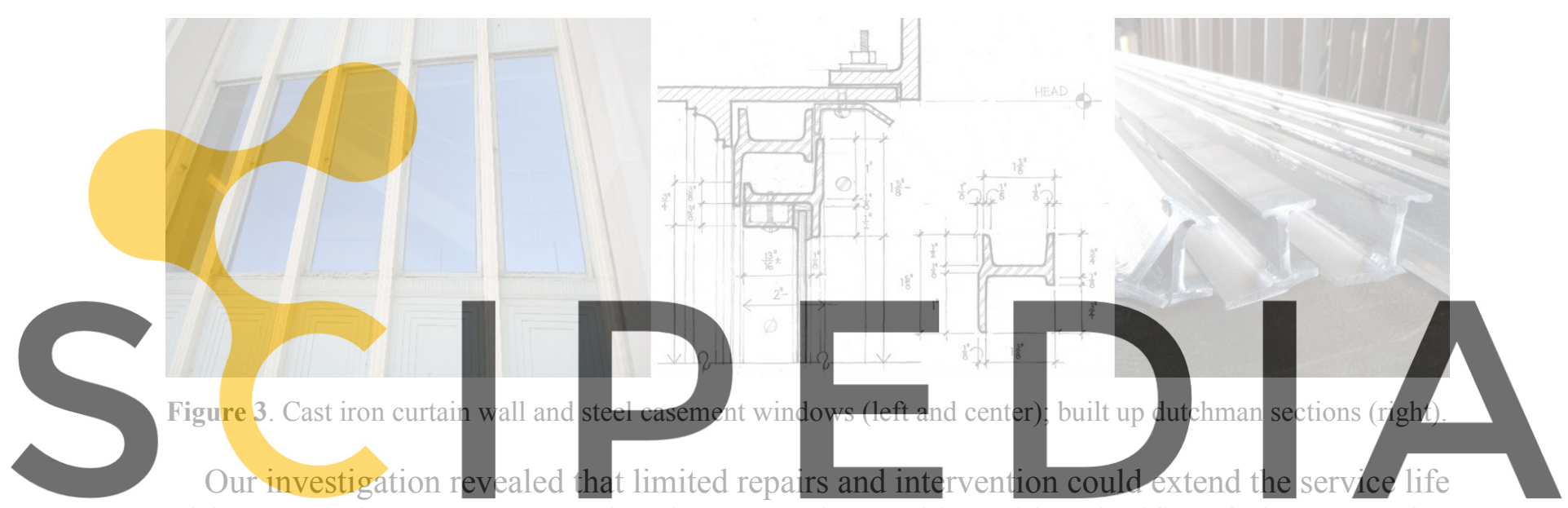

of the system, but a more comprehensive restoration could provide a significantly longer service

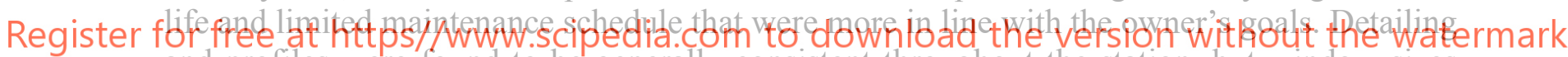
and profiles were found to be generally consistent throughout the station, but window sizes varied. The original manufacturer of the windows was determined through archival research, and product data, including original profiles, was located in historic product literature.

A comprehensive facade restoration program, including the stone masonry facade, steel frame windows, and cast iron curtain wall, began in 2012. The restoration scope included offsite restoration of the steel sash and frames, including comprehensive glass replacement, and in-situ restoration of the cast iron curtain wall. Coating removal was accomplished by abrasive blasting with a garnet media to achieve SSPC-SP10 (near white metal blast with a surface profile between 1 and 2 mils). Where necessary, dutchmen were created by building up steel plates and stitch welding them to mimic the original profile. The original steel was tested for weldability and a weld procedure was provided. A high performance coating system was applied to the blasted surface, consisting of a zinc-rich primer, epoxy intermediate coat, and fluoropolymer top coat. Finally, a blast and solar protection film was applied to the new glass prior to being glazed into the restored sash. To improve the overall thermal performance of the building, custom fabricated aluminum storm windows were installed on the interior of the building at office locations. 

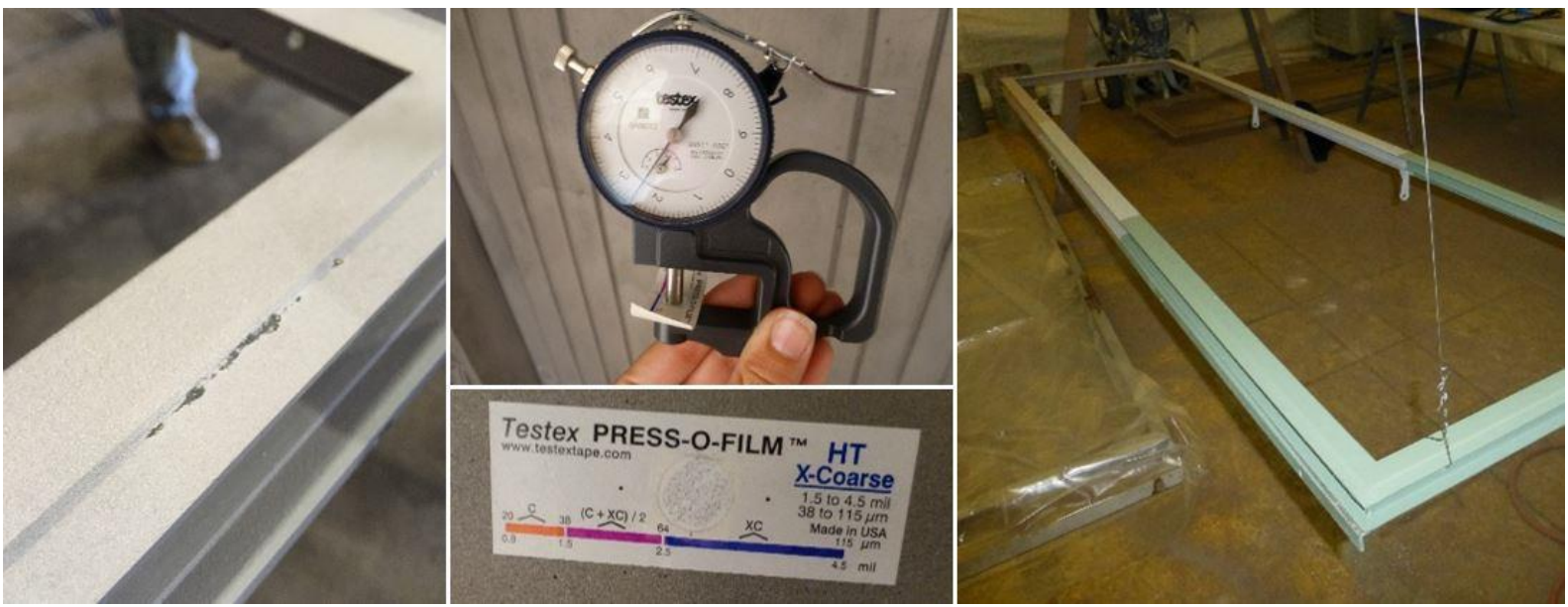

Figure 4. Steel frame blasting and surface profile measurement (left and center); coating mockup (right).

Several challenges were encountered at the beginning of the project that had to be resolved. Hazardous materials were found in concealed portions of the window assembly that required remediation. In addition, the weather-stripping had to be custom fabricated, as an off-the-shelf product replicating the profile could not be located by the contractor. A comprehensive quality control and quality assurance program was also established that included inspection and surface profile measurements of the window frames following blasting, and coating thickness measurements following each layer of coating application.

\section{Conclusions}

A successful historic window restoration project window conditions and the owner's expectat
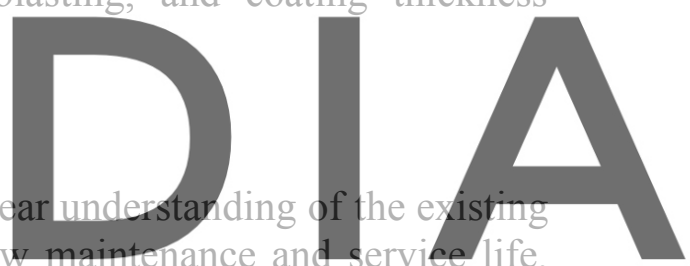

When possible, a comprehensive investigation of the existing windows can more accurately

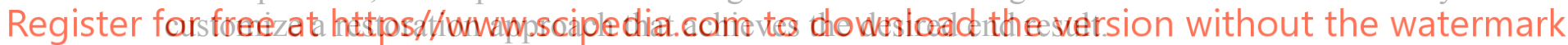

ORCIID

Edward A. Gerns: http://orcid.org/0000-0003-3640-4114

Sarah K. Van Domelen: http://orcid.org/0000-0002-1171-7862

\section{References}

Rex, J. and Society for Protective Coatings. (2000). Systems and Specifications, SSPC Painting Manual: Volume 2. Pittsburgh, PA: SSPC.

Sweet's Catalogue Service, Division of F. W. Dodge Corporation (1932). Sweet's Architectural Catalogues. New York, NY. 